\title{
Forward-viewing echoendoscope is useful for recanalization of postoperative biliary anastomotic atresia in endosonography-guided biliary drainage
}

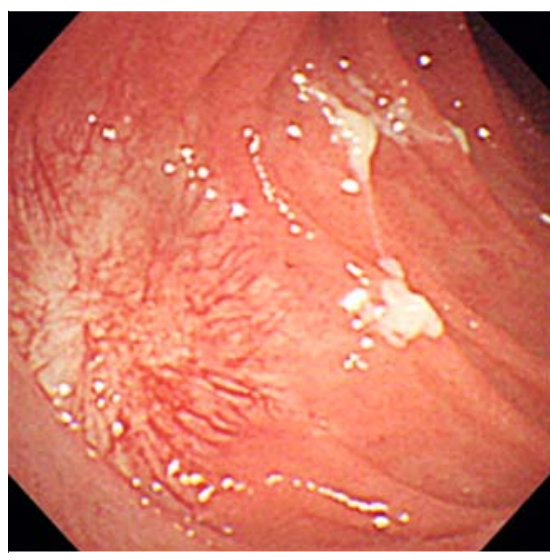

- Fig. 1 Endoscopic image showing complete atresia of the anastomosis site between the bile duct and jejunum, which was covered by jejunal mucosa.

One possible cause of biliary peritonitis and stent migration as adverse events of transgastrohepatic endosonographyguided biliary drainage (EUS-BD) [1] is a puncture site in the stomach wall and liver that is not fixed. Magnetic compression anastomosis (MCA) is applied to fix two organs, the gastrointestinal tract and the bile duct $[2,3]$. Herein, we present an alternative technique to fix these organs without MCA through recanalization of postoperative biliary anastomotic atresia with EUS-BD using a forwardviewing echoendoscope.

A 78-year-old man who underwent pancreatoduodenectomy because of cholangiocarcinoma was admitted with retrograde cholangitis. We tried to insert internal-external drainage tubes as percutaneous transhepatic biliary drainage tubes; however, the guidewire could not be inserted through the bile duct owing to complete atresia of the anastomosis site ( $\triangleright$ Fig. 1 ).

We then performed EUS-BD with a forward-viewing echoendoscope (TGFUC260 J, EU-ME1; Olympus Medical Systems, Tokyo, Japan) ( $\triangleright$ Fig. 2 ; $\triangleright$ Video 1 ). We identified the anastomosis site by endoscopy and confirmed by endoscopic

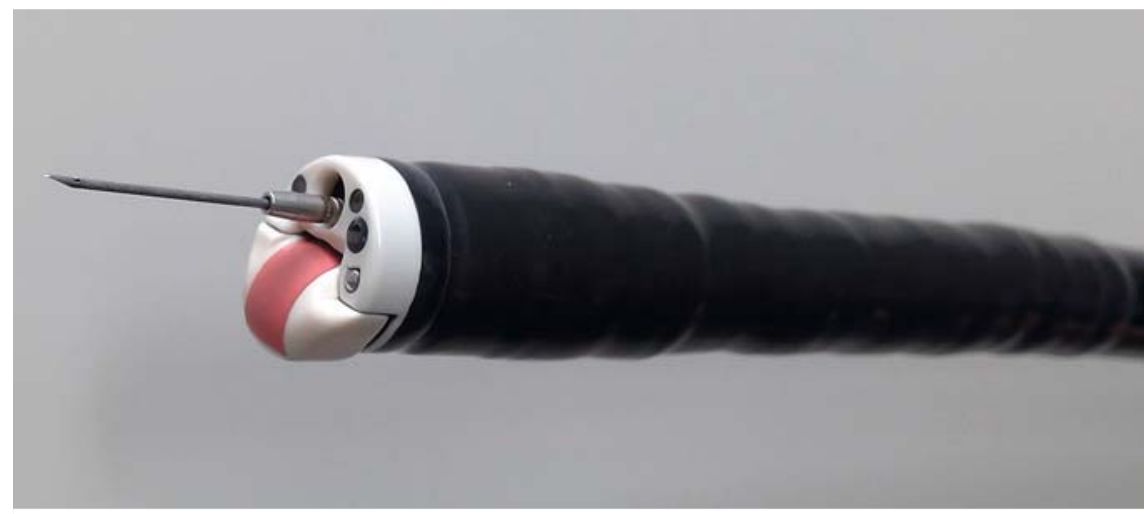

- Fig. 2 Photograph of the forward-viewing echoendoscope (TGF-UC260 J, EU-ME1; Olympus Medical Systems, Tokyo, Japan).

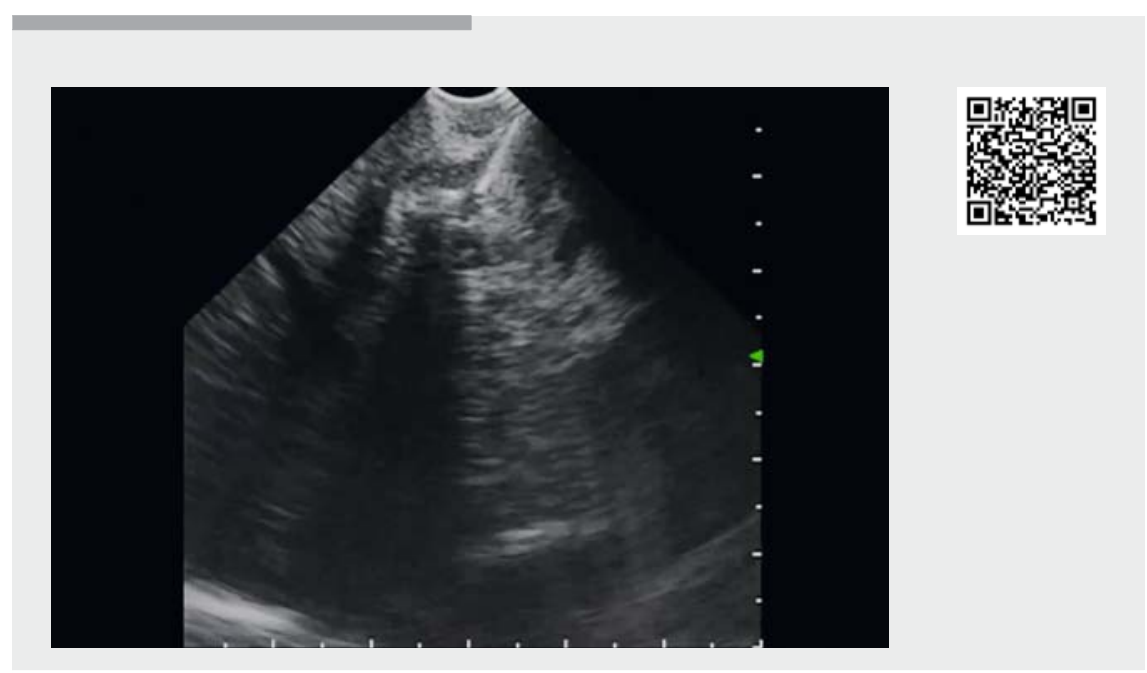

Video 1 A forward-viewing echoendoscope can enable a more vertical approach to the anastomosis site and help establish a rigid connection between the jejunum and bile duct in endosonography-guided biliary drainage.

ultrasound that the guidewire that was inserted through a percutaneous transhepatic approach was in the bile duct. We punctured the bile duct at the anastomosis site with a puncture needle and placed the guidewire into the bile duct. Although we tried to dilate the bile duct with a balloon dilator, the device could not go through the needle tract. Therefore, the bile duct was dilated with a wire-guided diathermic dilator. We rein- serted the balloon dilator and exchanged it initially for a plastic stent (QuickPlaceV; Olympus Medical Systems) (> Fig. 3) and subsequently for a wide-caliber stent, before adding another stent to dilate the recanalization route ( $\mathbf{F i g . 4}$ ). No adverse events of EUS-BD were observed. One year after EUS-BD was performed, the patient was free from all stents ( Fig. 5). 


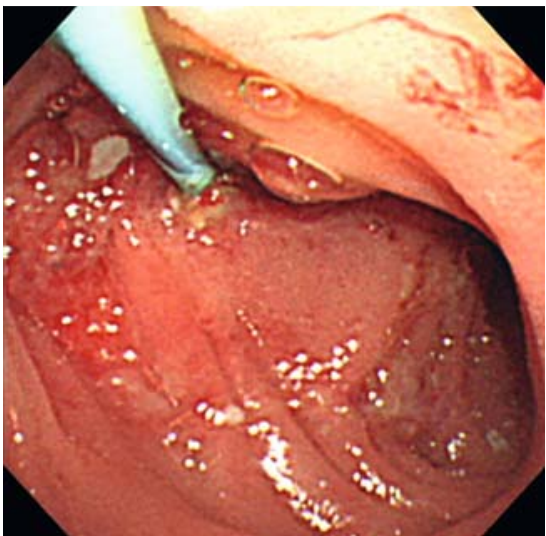

- Fig. 3 Endoscopic image immediately following the exchange of a balloon dilator with a 7-Fr straight plastic stent with a length of $5 \mathrm{~cm}$.

A forward-viewing echoendoscope may allow us to approach the anastomosis site more vertically and shorten the puncture distance, contributing to the feasibility and safety of the procedure [4].

Endoscopy_UCTN_Code_TTT_1AS_2AD

Competing interests

Toshio Uraoka has received lecture fees from Olympus Medical Systems.

The authors

\section{Takehiro Shimizu ${ }^{1,2}$, Ken Sato ${ }^{1}$, Takahiro} Abe $^{3}$, Dan Zennyoji ${ }^{1}$, Katsutoshi Ishida ${ }^{1}$, Koki Hoshi $^{1,4}$, Toshio Uraoka ${ }^{1}$

1 Department of Gastroenterology and Hepatology, Gunma University Graduate School of Medicine, Gunma, Japan

2 Department of Gastroenterology, Isesaki Municipal Hospital, Gunma, Japan

3 Department of Gastroenterology, Japanese Red Cross Maebashi Hospital, Gunma, Japan

4 Department of Gastroenterology, Dokkyo Medical University, Tochigi, Japan

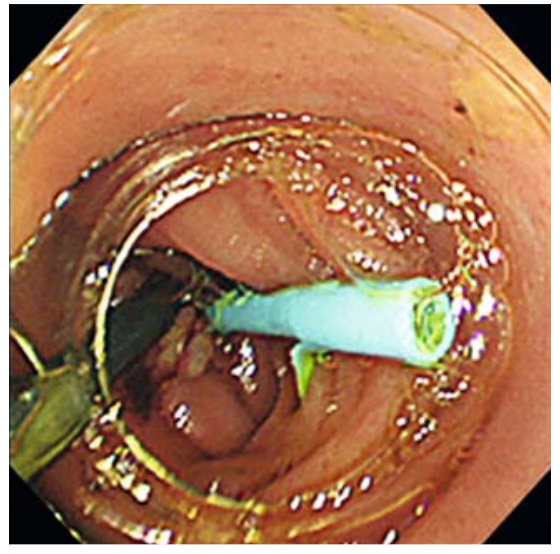

Fig. 4 Endoscopic image 5 months after endosonography-guided biliary drainage after the recanalization route had been dilated with 8.5-Fr and 7-Fr straight plastic stents with lengths of $5 \mathrm{~cm}$.

Corresponding author

\section{Ken Sato, MD, PhD}

Department of Gastroenterology and Hepatology, Gunma University Graduate School of Medicine, 3-39-22 Showa-machi, Maebashi, Gunma 371-8511, Japan

Fax: +81-272-208127

satoken@gunma-u.ac.jp

\section{References}

[1] Mukai S, Itoi T, Sofuni A et al. EUS-guided antegrade intervention for benign biliary diseases in patients with surgically altered anatomy (with videos). Gastrointest Endosc 2019; 89: 399-407

[2] Matsuura R, Ueno T, Tazuke Y et al. Magnetic compression anastomosis for postoperative biliary atresia. Pediatr Int 2017; 59: 737-739

[3] Itoi T, Kasuya K, Sofuni A et al. Magnetic compression anastomosis for biliary obstruction: review and experience at Tokyo Medical University Hospital. J Hepatobiliary Pancreat Sci 2011; 18: 357-365

[4] Hara K, Yamao Y, Hijioka S et al. Prospective clinical study of endoscopic ultrasoundguided choledochoduodenostomy with direct metallic stent placement using a forward-viewing echoendoscope. Endoscopy 2013: 45: 392-396

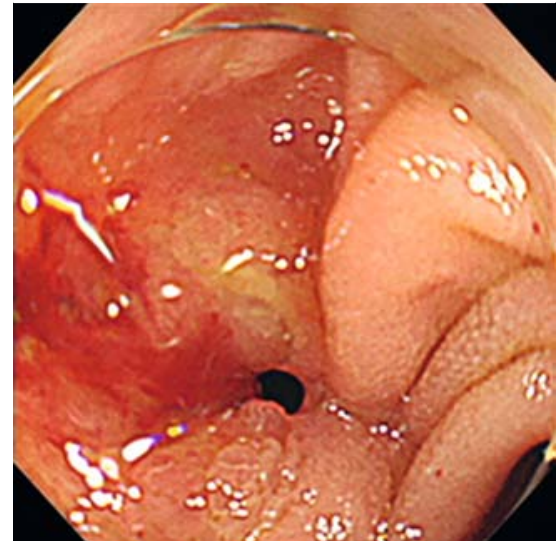

- Fig. 5 Endoscopic image 1 year after endosonography-guided biliary drainage showing the recanalization route that remained open after the patient was free from all stents.

\section{Bibliography}

Endoscopy 2020; 52: E437-E438

DOI $10.1055 / \mathrm{a}-1158-8408$

ISSN 0013-726X

published online 12.5 .2020

(c) 2020. Thieme. All rights reserved.

Georg Thieme Verlag KG, Rüdigerstraße 14, 70469 Stuttgart, Germany

\section{ENDOSCOPY E-VIDEOS}

https://eref.thieme.de/e-videos

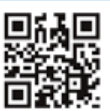

Endoscopy E-Videos is a free access online section, reporting on interesting cases and new techniques in gastroenterological endoscopy. All papers include a high quality video and all contributions are freely accessible online.

This section has its own submission website at https://mc.manuscriptcentral.com/e-videos 